\title{
WHAT ARE ANAEROBIC COCCI?
}

\author{
B. WATt AND Eleanor P. JACK \\ Central Microbiological Laboratories, Western General Hospital, \\ Edinburgh EH4 $2 X U$
}

A t present, the classification of obligately anaerobic cocci of clinical interest is in a state of confusion. Different authorities classify these organisms into different species, even different genera, and some workers allow inclusion of micro-aerophilic or $\mathrm{CO}_{2}$-requiring strains (see Smith, 1975). The absence of clear guidelines for characterisation is a constant source of discouragement to the clinical microbiologist and this has held back studies on the role of these organisms in health and disease.

As part of a study of methods for the isolation and characterisation of obligately anaerobic cocci of clinical interest, we found it necessary first to develop a clear definition that separates the obligately anaerobic cocci from micro-aerophilic or $\mathrm{CO}_{2}$-requiring strains. The present paper sets out the evidence for a provisional definition of " anaerobic cocci" that might allow studies on these organisms to be more soundly based.

\section{MATERIALS AND METHODS}

Strains. The following strains, representative of various Hare groups and labelled anaerobic cocci, were obtained from the National Collection of Type Cultures (NCTC), Central Public Health Laboratory, Colindale Avenue, London NW9 5HT: Hare Group I, no. NCTC9801; Group III, nos. NCTC9803 and NCTC9814; Group IV, nos. NCTC9804 and NCTC9815; Group V, nos. NCTC9805 and NCTC9816; Group VIa, nos. NCTC9806 and NCTC9817; Group VIb, no. NCTC9807; Group VIIa, no. NCTC9808; Group VIIb, nos. NCTC9809 and NCTC9819; Group VIII, nos. NCTC9810 and NCTC9820; and Group IX, nos. NCTC9811 and NCTC9821.

Twenty-one strains of cocci were received from Dr P. N. Edmunds and colleagues, Victoria Hospital, Kirkcaldy; two strains were received from Dr F. J. Bone, Dumfries Royal Infirmary; one strain each of Peptostreptococcus anaerobius, Peptococcus asaccharolyticus and an uncharacterised " anaerobic streptococcus" were received from Dr A. T. Willis, Public Health Laboratory, Luton; one strain of Veillonella parvula and one of V. gazogenes were received from Dr W. P. Holbrook, Manchester; 108 strains of cocci were isolated from clinical specimens at the Central Microbiological Laboratories, Edinburgh; and 90 strains were isolated from the genital tracts of women attending a family planning clinic in Edinburgh. A total of 226 strains were examined in the first instance. The test strains were subcultured in cooked-meat broth (CMB).

Gram staining. Smears of solid and liquid cultures of the test strains were stained by Kopeloff and Beerman's modification of Gram's method (see Cruickshank et al., 1975, p. 35).

Culture media. Cooked-meat broth was prepared as described by Cruickshank et al. (1975, p. 122), but the broth component was Nutrient Broth No. 2 (Oxoid); immediately before use it was steamed at $100^{\circ} \mathrm{C}$ for $30 \mathrm{~min}$. to remove dissolved air and then cooled rapidly to $37^{\circ} \mathrm{C}$. Nutrient Broth No. 2 was also used as a diluent in MIC studies. Horse blood agar (HBA) was prepared as follows. Agar water was prepared by dissolving $120 \mathrm{~g}$

Received 18 Apr. 1977; accepted 13 May 1977.

J. MED. MICROBIOL.—VOL: 10 (1977) 
Agar No. 3 (Difco) in 6 litres of tap water by autoclaving at $121^{\circ} \mathrm{C}$. Nutrient broth was prepared by dissolving $320 \mathrm{~g}$ Proteose Peptone No. 3 (Difco), $320 \mathrm{~g}$ Lab Lemco powder, and $160 \mathrm{~g}$ sodium chloride in 2 litres of tap water by steaming. Six litres of agar water were added to 2 litres of nutrient broth, the $p \mathrm{H}$ was adjusted to 7.3 , and the molten medium was dispensed in $500-\mathrm{ml}$ amounts and autoclaved at $121^{\circ} \mathrm{C}$ for $20 \mathrm{~min}$. These aliquots were re-melted by autoclaving, and after cooling to approximately $50^{\circ} \mathrm{C}$, horse blood $(10 \%)$ was added; after thorough mixing, molten medium was poured into plates. Columbia blood agar (CBA) plates were prepared with Columbia Blood Agar Base No. $2(1.2 \%)$ enriched with horse blood $(10 \%)$. This was supplemented with neomycin and menadione (final concentrations of $70 \mu \mathrm{g}$ per $\mathrm{ml}$ and $1 \mu \mathrm{g}$ per ml respectively) to give neomycin blood agar. The blood and supplements were added after autoclaving. Heated blood agar was prepared by heating horse blood $(5 \%)$ in Columbia Blood agar Base to $75^{\circ} \mathrm{C}$ for $10 \mathrm{~min}$. before pouring. Nonfermenting (NF) medium (Watt, to be published) was prepared as follows: $20 \mathrm{~g}$ Proteose Peptone No. 3 (Difco), $10 \mathrm{~g}$ Yeast Extract (Oxoid), $5 \mathrm{~g}$ sodium chloride, $2.5 \mathrm{~g}$ sodium succinate and $12 \mathrm{~g}$ agar were added to 1 litre distilled water, steamed until dissolved (approximately $30 \mathrm{~min}$.), and then autoclaved. The $p \mathrm{H}$ was adjusted to $7 \cdot 1$ before pouring.

Blood. In the early part of the study, defibrinated horse blood was supplied by Oxoid; latterly it was supplied by Gibco Bio-Cult Laboratories, Washington Road, Paisley. Outdated human blood was supplied by the Blood Transfusion Service; each $500-\mathrm{ml}$ volume of the human-blood preparation consisted of $430 \mathrm{ml}$ of whole blood and $70 \mathrm{ml}$ of water containing $2 \mathrm{~g}$ disodium citrate and $1.7 \mathrm{~g}$ dextrose.

Haemolysis. Haemolysis on Columbia Blood Agar (with $10 \%$ horse or human blood) was checked after incubation for $48 \mathrm{~h}$.

Chemicals. Menadione was supplied by Sigma, London, and sodium succinate by Hopkin and Williams, Chadwell Heath, Essex.

Anaerobic jar procedure. The standard anaerobic procedure of Collee et al. (1972) was followed, with Baird and Tatlock (BTL) anaerobic jars. Preliminary subculture of strains was performed in jars equipped with one catalyst sachet; more demanding studies (see below) were performed in jars equipped with three sachets. All cultures were incubated in $90 \% \mathrm{H}_{2}$ with $10 \% \mathrm{CO}_{2}$ at $37^{\circ} \mathrm{C}$.

Incubation in carbon dioxide. Plates were incubated in an incubator that was continually flushed with a gas mixture of $10 \% \mathrm{CO}_{2}$ in air.

Gases. Cylinders of a special gas mixture of $\mathrm{H}_{2} \quad 90 \%$ with $\mathrm{CO}_{2} \quad 10 \%$ were supplied by British Oxygen Company Ltd. Cylinders of $\mathrm{CO}_{2}$ gas were supplied by Distillers Company Ltd.

\section{Metronidazole sensitivity tests}

Disk sensitivity tests. For preliminary testing, 10 colonies from a culture of the test strain on solid medium were spread evenly over the surface of a horse blood agar (HBA) plate with a standard loop. A 5- $\mu \mathrm{g}$ metronidazole disk was added and the zone of inhibition measured after incubation for $48 \mathrm{~h}$.

For detailed testing, duplicate plates of NF medium were seeded with $0.02 \mathrm{ml}$ inocula of a 48-h CMB culture of the test strain and spread with sterile spreaders of standard size. A $5-\mu \mathrm{g}$ metronidazole disk was applied to each seeded plate and the zone of inhibition measured after incubation for $48 \mathrm{~h}$.

Determination of minimum inhibitory concentration (MIC). Two-fold dilutions of a filter-sterilised solution of metronidazole were prepared in pre-steamed nutrient broth and added to molten NF medium at approximately $50^{\circ} \mathrm{C}$, together with $10 \%$ horse blood. After careful mixing, plates were poured. The range of final concentrations in the solid medium was 0.02 to $10 \mu \mathrm{g}$ metronidazole per ml. Antibiotic plates were seeded with the test strains, with a multiple inoculator delivering an inoculum of approximately $10^{5}$ c.f.u. Duplicate plates, together with control plates (without antibiotic) were seeded in parallel; appropriate control strains were also put up in parallel (see below). The plates were incubated under anaerobic conditions for $48 \mathrm{~h}$ at $37^{\circ} \mathrm{C}$ and the MIC was taken as the lowest concentration that totally inhibited bacterial growth. 
Control strains. Bacteroides fragilis no. NCTC9344 and an anaerobic coccus (lab. no. A/C 44) were used as controls for the antibiotic sensitivity tests, and $B$. fragilis, no. NCTC9344, was used as a control to check that satisfactory anaerobic conditions were achieved.

Metronidazole. Metronidazole powder of known potency was supplied by May and Baker Ltd. Disks of metronidazole $(5 \mu \mathrm{g})$, manufactured by Mast Laboratories, were also supplied by May and Baker.

\section{RESULTS}

\section{Clinical isolates}

We investigated a total of 205 clinical isolates. All of the strains were cocci that, on primary culture, had grown under anaerobic conditions but failed to grow aerobically. They were screened in our laboratory as follows.

(A) Each strain was subcultured on to heated blood agar and incubated for $24 \mathrm{~h}$ at $37^{\circ} \mathrm{C}$ in an atmosphere of $10 \% \mathrm{CO}_{2}$ in air.

(B) Two plates of horse blood agar (HBA) were seeded with each strain; one was incubated aerobically, the other anaerobically (see Methods) for $24 \mathrm{~h}$ at $37^{\circ} \mathrm{C}$.

(C) The sensitivity of each strain to metronidazole was determined by a disk diffusion test on HBA, with a $5-\mu \mathrm{g}$ disk of metronidazole.

The results (table I) show that 175 of the 205 strains grew under anaerobic conditions only, and were sensitive to metronidazole. Thirty were resistant to metronidazole and three of these grew under anaerobic conditions only, 10 grew aerobically and the remaining 17 grew in $10 \% \mathrm{CO}_{2}$ in air.

TABLE I

Gaseous requirements and metronidazole sensitivity of 207 clinical isolates of cocci

\begin{tabular}{|c|c|c|c|c|}
\hline \multirow[b]{2}{*}{$\begin{array}{l}\text { Number of } \\
\text { strains }\end{array}$} & \multicolumn{3}{|c|}{${ }^{*}$ Growth on solid media in } & \multirow[b]{2}{*}{$\begin{array}{l}\text { Susceptibility to } \\
\text { metronidazole } \uparrow\end{array}$} \\
\hline & air & $\begin{array}{c}\text { air } \\
\text { plus } \\
10 \% \mathrm{CO}_{2}\end{array}$ & $\begin{array}{c}90 \% \mathrm{H}_{2} \\
\text { plus } \\
10 \% \mathrm{CO}_{2}\end{array}$ & \\
\hline 10 & + & + & $\therefore-$ & $\mathbf{R}$ \\
\hline 17 & - & + & $\div$ & $\mathbf{R}$ \\
\hline 3 & - & - & $-t$ & $\mathrm{R}$ \\
\hline 175 & - & - & $\mathrm{i}^{-}$ & $\mathbf{S}$ \\
\hline
\end{tabular}

* All strains incubated overnight at $37^{\circ} \mathrm{C}$

$\div=$ Visible surface growth; $-=$ no growth

$\dagger \mathrm{R}=$ resistant, i.e., zone of inhibition $<15 \mathrm{~mm}$ after incubation for $24 \mathrm{~h} ; \mathrm{S}=$ sensitive: zone of inhibition $>15 \mathrm{~mm}$ after incubation for $24 \mathrm{~h}$.

A representative collection of 91 of our metronidazole-sensitive strains, together with the three apparently anaerobic metronidazole-resistant ("AAMR") strains were tested further as follows.

(1) Each strain was subcultured on to heated blood agar, and the plates were incubated for 7 days in $10 \% \mathrm{CO}_{2}$ in air at $37^{\circ} \mathrm{C}$. 
(2) The disk tests for sensitivity to metronidazole were repeated with the procedure (see Methods) in which standard inocula were tested on NF medium.

(3) The MIC of metronidazole was determined for each strain.

(4) Metronidazole-resistant strains were also tested for their ability to grow on plates of NF medium containing $500 \mu \mathrm{g}$ metronidazole per ml.

The results (table II) show that all three of the AAMR strains grew within 7 days on heated blood agar in $10 \% \mathrm{CO}_{2}$ in air. These AAMR strains were able to grow satisfactorily in the presence of metronidazole at a concentration of $500 \mu \mathrm{g}$ per ml. The remaining 91 strains did not grow in $10 \% \mathrm{CO}_{2}$ even after incubation for 7 days and all were sensitive to metronidazole; of these, 90 strains had MIC values that did not exceed $2.5 \mu \mathrm{g}$ per ml, and one strain had an MIC of $5 \mu \mathrm{g}$ per $\mathrm{ml}$.

TABLE II

Growth and susceptibility to metronidazole of 94 clinical isolates of cocci initially considered to be anaerobic

\begin{tabular}{c|cc}
\hline Number of strains & $\begin{array}{c}\text { Growth on solid media in } \\
\text { air plus } 10 \% \mathrm{CO}_{2}{ }^{*}\end{array}$ & $\begin{array}{c}\mathrm{MIC} \text { of metronidazole } \\
(\mu \mathrm{g} \text { per ml })\end{array}$ \\
\hline 3 & + & $\begin{array}{c}>500 \\
90\end{array}$ \\
1 & - & 2.5 or less \\
\hline
\end{tabular}

* Plates incubated for up to 7 days (see Methods).

\section{Reference strains}

A total of 21 reference strains tested included 17 NCTC strains, one strain of Peptostreptococcus anaerobius and one strain of Peptococcus asaccharolyticus from Dr Willis, and two strains of Veillonella spp. from Dr Holbrook. Preliminary testing (see above) showed that the four defined strains from Dr Willis and Dr Holbrook were obligate anaerobes, and were sensitive to metronidazole. Of the 17 NCTC strains, 13 appeared to be obligate anaerobes; one strain grew aerobically and three strains grew in $10 \% \mathrm{CO}_{2}$ in air. Of the 13 obligate anaerobes, all but one (NCTC9819) were sensitive to metronidazole. All of the four " non-anaerobic " strains were resistant to metronidazole (see table III).

All of the strains were tested further, as outlined in (1)-(4) above. The results showed that strain no. NCTC9819 was not an obligate anaerobe, but grew in $10 \% \mathrm{CO}_{2}$ after incubation for 7 days. This strain, and the other four "non-anaerobic" strains, were capable of growth on media containing $500 \mu \mathrm{g}$ metronidazole per $\mathrm{ml}$ and incubated anaerobically. The remaining 12 obligatelyanaerobic NCTC strains were all sensitive to metronidazole (MIC values less than $2.5 \mu \mathrm{g}$ per $\mathrm{ml}$ ). The two strains of Veillonella, the strain of Peptostreptococcus anaerobius and the strain of Peptococcus asaccharolyticus were all obligate anaerobes and were sensitive to metronidazole. 
TABLE III

Gaseous requirements and metronidazole sensitivity of 21 reference strains of anaerobic cocci

\begin{tabular}{|c|c|c|c|c|}
\hline \multirow[b]{2}{*}{$\begin{array}{l}\text { NCTC number } \\
\text { or label }\end{array}$} & \multicolumn{3}{|c|}{${ }^{*}$ Growth on solid media in } & \multirow[b]{2}{*}{$\begin{array}{l}\text { Susceptibility to } \\
\text { metronidazole } \dagger\end{array}$} \\
\hline & air & $\begin{array}{c}\text { air } \\
\text { plus } \\
10 \% \mathrm{CO}_{2}\end{array}$ & $\begin{array}{c}90 \% \mathrm{H}_{2} \\
\text { plus } \\
10 \% \mathrm{CO}_{2}\end{array}$ & \\
\hline 9801 & - & - & - & $\mathbf{S}$ \\
\hline 9803 & - & - & + & S \\
\hline 9804 & - & - & + & S \\
\hline 9805 & - & - & + & S \\
\hline 9806 & - & + & + & $\tilde{R}$ \\
\hline 9807 & + & + & + & $\mathbf{R}$ \\
\hline 9808 & - & - & + & s \\
\hline 9809 & - & + & + & $\mathbf{R}$ \\
\hline 9810 & - & - & + & $\mathrm{S}$ \\
\hline 9811 & - & - & + & $\mathrm{S}$ \\
\hline 9814 & - & -- & + & $\mathrm{S}$ \\
\hline 9815 & - & - & + & $\tilde{S}$ \\
\hline 9816 & - & - & + & $\mathrm{S}$ \\
\hline 9817 & - & + & + & $\mathbf{R}$ \\
\hline 9819 & - & $\ddagger$ & + & $\mathbf{R}$ \\
\hline 9820 & - & \pm & + & $\mathrm{s}$ \\
\hline 9821 & - & - & + & $\tilde{S}$ \\
\hline $\begin{array}{l}\text { Peptostreptococcus } \\
\text { anaerobius }\end{array}$ & - & - & + & $\mathrm{S}$ \\
\hline $\begin{array}{l}\text { Peptococcus } \\
\text { asccharolvticus }\end{array}$ & - & - & + & $\mathbf{S}$ \\
\hline $\begin{array}{l}\text { asaccharolyticus } \\
\text { Veillonella } \\
\text { parvula }\end{array}$ & - & - & + & $\mathbf{S}$ \\
\hline $\begin{array}{l}\text { peillonella } \\
\text { gazogenes }\end{array}$ & - & - & + & $\mathrm{S}$ \\
\hline
\end{tabular}

* All strains incubated overnight at $37^{\circ} \mathrm{C}$.

$\dagger \mathrm{R}=$ resistant: zone of inhibition less than $15 \mathrm{~mm}$ after incubation for $48 \mathrm{~h} ; \mathrm{S}=$ sensitive: zone of inhibition greater than $15 \mathrm{~mm}$ after incubation for $48 \mathrm{~h}$. (see text).

$\ddagger$ This strain was subsequently shown to grow in $10 \% \mathrm{CO}_{2}$ in air after prolonged incubation

\section{Haemolysis on blood agar}

None of the 191 obligately-anaerobic metronidazole-sensitive cocci (clinical isolates or reference strains) showed any haemolysis on horse or human blood agar. Three of the $\mathrm{CO}_{2}$-requiring metronidazole-resistant clinical isolates showed good haemolysis on horse-blood agar, as did strain no. NCTC9807, an aerobic organism.

\section{Disk sensitivity tests}

Differentation between metronidazole-sensitive and metronidazole-resistant strains was clear-cut on the basis of disk sensitivity testing. All resistant organisms had inhibition zones of less than $10 \mathrm{~mm}$, whereas sensitive strains gave zones of $20 \mathrm{~mm}$ or more.

\section{Gram reaction}

Of the 196 strains of obligately anaerobic cocci $(175$ clinical isolates and 21 reference strains), many showed considerable variability when stained by Gram's 
method; six were consistently gram-negative, 150 were consistently grampositive, and the remaining 40 strains were gram-variable. The morphology of the strains was not characteristic: only 40 strains showed typical streptococcal morphology whilst the remainder appeared in clumps, with short chains, in gram-stained smears. In many cases, there was considerable pleomorphism.

\section{Discussion}

There has been great interest in recent years in the role of anaerobic bacteria in human health and disease, yet this interest has largely been confined to the clostridia and to the gram-negative anaerobic bacilli. The obligately anaerobic cocci have received little attention, in spite of several reports attesting their importance in man (e.g. Pien, Thompson and Martin, 1972; Lambe, Vroon and Rietz, 1974).

The reason for the scanty attention received by these organisms may lie in the confusion surrounding their classification. In recent years, differing and conflicting schemes for the classification of anaerobic cocci have been proposed by several workers including Prévot and Fredette (1966), Holdeman and Moore (1972), and Buchanan and Gibbons (1974). The confused field has been reviewed by Smith (1975). The situation is further complicated: many cocci that on primary culture only grow anaerobically may grow well in $10 \% \mathrm{CO}_{2}$ in air on subculture, and some of the classification schemes allow inclusion of micro-aerophilic or $\mathrm{CO}_{2}$-requiring strains, e.g., Peptostreptococcus intermedius (Smith, 1975).

We are at present engaged on a study of the isolation, characterisation and antibiotic susceptibility of obligately anaerobic cocci of clinical interest. In the early stages of our study, it was necessary to formulate a definition that included all of the obligately anaerobic strains but excluded any strains of cocci that were not obligate anaerobes. As we collected more strains, several points became clear in our attempts to define anaerobic cocci. (1) Many apparently anaerobic strains grew well in $10 \% \mathrm{CO}_{2}$ on subculture, although some required incubation for up to 7 days to develop visible colonies on solid media. (2) All obligately anaerobic strains appeared sensitive to metronidazole in a disk diffusion test. (3) All aerobic or $\mathrm{CO}_{2}$-requiring strains were resistant to metronidazole.

The results of more detailed studies on a large number of clinical isolates and reference strains confirm these preliminary findings. All of the obligately anaerobic cocci (both gram-positive and gram-negative strains), were sensitive to metronidazole in vitro, both in disk diffusion tests and in MIC determinations. All of the remaining cocci grew in $10 \% \mathrm{CO}_{2}$ within 7 days and were resistant to metronidazole. These latter strains may be of as much importance in human health and disease as the obligately anaerobic strains, but they form a separate and clearly distinguished group.

One of the problems involved in the classification of obligately anaerobic cocci is the absence of a satisfactory collection of reference strains. Our results 
show that of the 17 strains of " anaerobic cocci" lodged by Hare, used in his early scheme of classification (Thomas and Hare, 1954) and listed in the 1974 NCTC catalogue, only 12 behave as obligate anaerobes in our hands. These strains are sensitive to metronidazole. The remaining five strains all grow in $10 \% \mathrm{CO}_{2}$ within 7 days and are resistant to high concentrations of metronidazole. There is a clear need for a well-documented reference collection of obligately anaerobic cocci derived from clinical isolates, with agreed biochemical reactions, to form a basis for comparative studies.

We have found that obligately anaerobic cocci have little or no characteristic colonial appearances. They exhibit variable staining patterns and pleomorphism in Gram-stained smears, are non-haemolytic and have a wide range of antibiotic susceptibility patterns (Watt, in preparation). In the present paper we have avoided the use of any of these parameters in putting forward the provisional definition of anaerobic cocci as "Cocci that grow well under satisfactory conditions of anaerobiosis and do not grow on suitable solid media in $10 \% \mathrm{CO}_{2}$ in air even after incubation for 7 days at $37^{\circ} \mathrm{C}$."

This definition sets out clear criteria for basic studies on these organismscriteria that are valid for gram-positive and gram-negative cocci of clinical interest. The definition has the practical disadvantage that an incubation period of 7 days is required before a given strain can be regarded as an anaerobic coccus; this is too long for the practising clinical microbiologist. The use of metronidazole sensitivity testing (a procedure that can be completed within 24 or $48 \mathrm{~h}$ ) provides both valuable chemotherapeutic information and an effective screening procedure. In our experience, anaerobic cocci are all sensitive to metronidazole. Accordingly, at the time of writing, all metronidazole-sensitive strains can be assumed to be anaerobic cocci, and all resistant strains must be checked further; we have not yet encountered a metronidazole-resistant anaerobic coccus. Clearly it would be unwise to rely solely upon metronidazole sensitivity in the definition of anaerobic cocci; with increasing clinical use of the drug there is a possibility that resistance may develop amongst obligately anaerobic bacteria. The combination of a basic definition with a useful screening test seems to cover this possibility, and we follow attempts to determine the mode of action of the drug with interest (see Edwards, 1977).

The clinical microbiologist, faced with terminological confusion, often resorts in despair to the use of the term " anaerobic streptococci " to cover all obligately anaerobic cocci isolated from clinical samples, yet many strains fail to show streptococcal morphology and may not be obligate anaerobes. We submit that the term "anaerobic cocci" for organisms that conform to our working definition provides a more sound basis for characterisation in the diagnostic laboratory and for further studies of these organisms in human health and disease.

\section{SUMMARY}

Criteria are suggested for the definition of " anaerobic cocci" as a general term to include all obligately anaerobic cocci. Such a definition draws a clear distinction between obligately anaerobic and micro-aerophilic strains and might 
form a basis both for characterisation of these organisms in the diagnostic laboratory and for further studies on their taxonomy and pathogenicity.

The authors acknowledge the importance of initial observations and suggestions by Mrs F. V. Brown, thank Miss Fiona M. Gibb and Mrs Gillian M. Penman for technical support and are grateful to Prof. J. G. Collee for helpful comments. B. W. thanks Messrs May and Baker Ltd for financial help towards the cost of this study and for supplies of metronidazole.

\section{REFERENCES}

Buchanan, R. E. AND GibBons, N. E. 1974. Bergey's manual of determinative bacteriology, 8th ed., Baltimore, p. 517.

Collee, J. G., WATt, B., Fowler, E. B. ANd Brown, R. 1972. An evaluation of the Gaspak system in the culture of anaerobic bacteria. J. appl. Bact., 35, 71.

Cruickshank, R., Duguid, J. P., Marmion, B. P. and Swain, R. H. A. 1975. Medical microbiology, 12th ed., Edinburgh and London, vol. 2.

EDWARDS, D. I. 1977. The action of metronidazole on DNA. J. antimicrob. Chemother., 3, 43.

Holdeman, L. V. ANd Moore, W. E. C. 1972. Anaerobe Laboratory Manual, Virginia Polytechnic Institute Anaerobe Laboratory, Blacksburg.

Lambe, D. W., Vroon, D. H. AND RIETZ, C. W. 1974. Infections due to anaerobic cocci. In Anaerobic bacteria, role in disease, edited by A. Balows, R. M. Dehaan, V. R. Dowell and L. B. Guze, Illinois, p. 585.

Pien, F. D., Thompson, R. L. AND Martin, W. J. 1972. Clinical and bacteriologic studies of anaerobic gram-positive cocci. Mayo Clin. Proc., 47, 251.

Prévot, A. R. AND Fredette, V. 1966. Manual for the classification and determination of the anaerobic bacteria, Philadelphia.

SMITH, L. DS. 1975. Anaerobic cocci. In The pathogenic anaerobic bacteria, 2nd ed., Springfield.

Thomas, C. G. A. and Hare, R. 1954. The classification of anaerobic cocci and their isolation in normal human beings and pathological processes. J. clin. Path., 7, 300. 